\title{
Effect of Contaminant Flow-rate and Applied Voltage on the Current Density and Electric Field of Polymer Tracking Test
}

\author{
F. L. Muhamedin, M.A.M. Piah, N.A. Othman and Nasir Ahmed Algeelani \\ Institute of High Voltage and High Current, Faculty of Electrical Engineering, \\ Universiti Teknologi Malaysia, Malaysia
}

\begin{tabular}{l} 
Article Info \\
\hline Article history: \\
Received Oct 2, 2015 \\
Revised Dec 20, 2015 \\
Accepted Jan 6, 2016 \\
\hline Keyword: \\
Current Density \\
Electric Field \\
Finite Element Software \\
IEC 60587 \\
Polymeric insulator \\
Surface Discharges
\end{tabular}

\section{Article history:}

Received Oct 2, 2015

Revised Dec 20, 2015

Accepted Jan 6, 2016

\begin{abstract}
Electrical failure due to surface discharge on the insulation material will cause material degradation and eventually lead to system failure. The flow of leakage current (LC) on the insulator surface under wet contamination is used to determine the material degradation level. According to IEC 60587 standard, LC exceeding $60 \mathrm{~mA}$ for more than two seconds is considered as failure. In this study, the electric field and current density distributions on the linear low-density polyethylene (LLDPE) and natural rubber blend material have been analyzed using finite element method (FEM) analysis. The physical parameters used in FEM simulation were applied with voltage and contaminant flow rate, in accordance to contaminant conductivity. Tracking test condition according to IEC 60587 standardhas been applied as proposed by the reference work in simulation using Quick Field FEM software. The results show that the electric field and current density would become critical in higher applied voltage and contaminant flow rate. The highest average and highest maximum current density and electric field are found in both applied voltage of $6 \mathrm{kV}$ and contaminant flow rate of $0.90 \mathrm{mlmin}^{-1}$.
\end{abstract}

Copyright (C) 2016 Institute of Advanced Engineering and Science. All rights reserved.

\section{Corresponding Author:}

F. L. Muhamedin, Institute of High Voltage and High Current, Faculty of Electrical Engineering, Universiti Teknologi Malaysia, Universiti Teknologi Malaysia, 81310 Skudai, Johor, Malaysia. Email: fliyana5@live.utm.my

\section{INTRODUCTION}

In high voltage instruments, outdoor insulator failure due to degradation is mostly caused by insulator pollution, acid rain, ultraviolet radiation and wet contamination.Polymer-based materials commonly face surface discharge due to aging [1]. Surface discharge is a phenomenon of failure on insulating surface due to intensive leakage current (LC) flow. The material surface commonly shows a low capacitive leakage current in dry conditions with the presence of dirt. Under wet conditions, insulator surface usually suffers flow of leakage current [2]. Wet layer contaminant is thinnest near the ground electrode due to evaporation. Simultaneous flow of leakage current will heat up the insulating surface and form dry band. When air-gap reaches the critical flashover voltage across the dry band, arc sparks will be formed, whichburns the insulator material and creates carbonized track. Electrical tracking due to progressive degradation of the insulating surface by surface discharges will lead to insulation failure when a formation of carbonized track connects the electrodes to form conducting paths.

The electrical and mechanical properties of polymer-based materials have been continuously improved in this field. Addition of filler into polymer blends such as microfiller and nanofilleroffers a promising outcome for insulation materials $[3,4]$. Apart from that, the material treatment, texture of the insulator surface and materials process have been the interest among researchers to investigate [5-7]. However, the improvement on the electrical properties of materials can only enhance the years of service. 
The degradation level of polymer due to electrical tracking can be measured using several parameters which are leakage current, carbon track development, erosion depth, weight loss, thermal conductivity and hydrophobicity loss. Online monitoring LC is widely used by researchers to investigate the tracking and erosion resistance of materials [8-10]. Leakage current indicates the surface discharge activity, thus LC is proportional to the degree of material degradation [11].

The simulation of electrical stresses due to water droplet and void has been conducted by a number of researchers [12-14]. It is known that electric field, admittance, and dielectric loss increase in a defective void insulator. When applied voltage is increased, the electric field intensity and current density loss would increase [12]. Tracking is more severe in defective samples, since the presence of surface contamination would increase the distortion of the electric field around the defect [14]. Electric field is enhanced at the contact edges between electrodes and polymer surface and at the triple point of polymer, water, and air when water droplet is placed at the center of the gap [13]. A water droplet on the surface of insulator will initiate corona discharges. Corona discharge is triggered by the presence of a local high electric field. The corona discharge is able to propagate along the water surface. Under applied high voltage, water layer is formed due to vibration of water droplets. When water layer covers the specimen surface, the conductivity of flow of leakage current can be detected. In this region, the current density is observed as non-uniform. Locally high current density between the droplets can result in the formation of dry bands [15]. This high current density between the droplets can result in the formation of dry bands. The current, $I$ can be calculated using Equation (1).

$$
I=\int J \mathrm{~d} A
$$

where $A$ is the area of the cross section of the insulator and $J$ is current density. The calculated current can be compared with the measured leakage current obtained from IPT test. Electric potential distribution along the insulator is dependent on both conductivity of pollution and location of pollution on the insulator surface. The impulse voltage for a polluted bottom surface is more critical than polluted upper surface [16].

Previously, the studies in the field simulation focused majorly in the partial discharge phenomena [17-18]. The analysis in field simulation of surface tracking is trivial. Therefore, there is a possibility to analyze the modelling of surface tracking in field work. In this study, the distributions of the electric field and current density on the insulator surface were investigated using Finite Element Software under wet condition. The materials used for analyseswere linear low-density polyethylene (LLDPE) and natural rubber blend material. The simulation of finite element analysis (FEA) was compliant with the test set-up configuration of IEC 60587 standard tracking and erosion test. The controlled parameters in the simulation were applied voltage, electric conductivity and permittivityof insulating sample and contaminant solution.

\section{RESEARCH METHOD}

\subsection{Material and Contaminant Solution Properties}

In this study, material properties of electric conductivity and relative permittivity of the samples, contaminant solution and air were required for simulation purpose. The relative permittivity and conductivity of the air were 1 and $2 \times 10^{-4} \mathrm{Sm}^{-1}$, respectively [19]. The relative permittivity of contaminant solution was 81 [20]. The formulated thermoplastic elastomer material was composed of Linear Low-Density Polyethylene with Natural Rubber (LLDPE/NR) with 80:20 ratio. The ratio of polymer blend of LLDPE/NR was selected because it canprovide good in electrical tracking and erosion resistance [21]. The estimation of conductivity of the test object was obtained from the measurement of polarization and depolarization current. The test object was charged for a sufficiently long time so that the charging response $f\left(t+t_{c}\right) \cong 0$, the dc conductivity $(\sigma)$ of the composite dielectric could be expressed as following equation.

$$
\sigma=\frac{\varepsilon_{r} \varepsilon_{o}}{C_{o} U_{o}}\left[i_{p}(t)-i_{d p}(t)\right]
$$

where $\varepsilon_{o}$ is free space dielectric constant $\left(8.854 \times 10^{-12} \mathrm{~F} / \mathrm{m}\right), C_{o}$ is capacitance of material, and $U_{o}$ is applied voltage $(1000 \mathrm{~V})$. 
Meanwhile, determinations of the inductance, capacitance, resistance (LCR) meter of the upper and bottom electrodes were carried out to measure the capacitance before using Equation (3) to obtain the permittivity of the insulator material. Table 1 shows the material properties for insulator sample.

$$
\varepsilon_{r}=\frac{C}{\varepsilon_{o}} \times \frac{d}{A}
$$

where $d$ is thickness of sample material $(1 \mathrm{~mm})$ and $A$ is area of sample affected $\left(50.27 \mathrm{~cm}^{2}\right)$

Table 1. Material properties

\begin{tabular}{ccc}
\hline Capacitance $(\mathrm{pF})$ & Relative Permittivity & Conductivity(S/m) \\
\hline 120.67 & 2.71 & $2.944 \mathrm{E}-12$ \\
\hline
\end{tabular}

The parameters used to study the electric field and current density distributions were contaminant flow rate and applied voltage. To indicate the change in contaminant flow rate in the simulation works, the conductivity of contaminant solution was used. According to the IEC 60587 standard, the volume of contaminated solution was set different for each contaminant flow rate. The conductivity of contaminant solution was changed correspondingly to the volume of contaminant solution based on contaminant flow rate. The volume $(V)$ of contaminant solution obtained for each contaminant flow rate is shown in Table 2 . The length $(l)$ of contaminant was $50 \mathrm{~mm}$ and measured between high voltage electrode and ground electrode, while the area $(A)$ of each contaminant was obtained using the equation below.

$$
A=\frac{V}{l}
$$

The resistance of contaminant solution for each contaminant flow rate was calculated using Equation (5) by inserting the resistivity equal to those $3.95 \Omega . m$ as stated in IEC 60587 standard [20].

$$
R=\frac{\rho l}{A}
$$

Then, the resistivity of each contaminant volume was calculated for the second time to obtain electric conductivity also by using Equation (5) with area sizing from Quick field ${ }^{\mathrm{Fm}}$ Simulation. The conductivity of contaminant was calculated by using Equation (6). Table 2 depicts the conductivity of contaminant solution for different contaminant flow rate.

$$
\sigma=\frac{1}{\rho}
$$

\begin{tabular}{|c|c|c|c|c|}
\hline Volume of contaminant $\left(\mathrm{cm}^{3}\right)$ & 0.15 & 0.30 & 0.60 & 0.90 \\
\hline Area of contaminant $\left(\mathrm{cm}^{2}\right)$ & 0.03 & 0.06 & 0.12 & 0.18 \\
\hline Length of contaminant $(\mathrm{cm})$ & 5.0 & 5.0 & 5.0 & 5.0 \\
\hline $\begin{array}{l}\text { Area of contaminant }\left(\mathrm{cm}^{2}\right) \\
\text { From Quickfield }{ }^{\mathrm{Fm}} \text { Simulation }\end{array}$ & 0.70 & 0.77 & 1.18 & 1.24 \\
\hline Resistivity $(\Omega . \mathrm{m})$ & 92.16 & 50.70 & 38.85 & 27.20 \\
\hline
\end{tabular}

where $R, \rho, l$ and $A$ are the resistance, resistivity, length of contaminant solution and area of contaminant solution, respectively.

Table 2. Electric conductivity of contaminant solution 


\subsection{FEM Simulation}

The electric field and current density distribution in the insulating model were solved using QuickField FEA software. The test configuration methods used for evaluating resistance to tracking and erosion, were based on IEC 60587 standard as a simulation reference model. Figure 1 presents the simulation drawing of two-dimensional (2D) plane parallel model. According to the inclined plane tracking method of IEC 60587 standard, a rectangular sample with size of $50 \mathrm{~mm}$ x $120 \mathrm{~mm}$ and thickness of $6 \mathrm{~mm}$ was used [22].

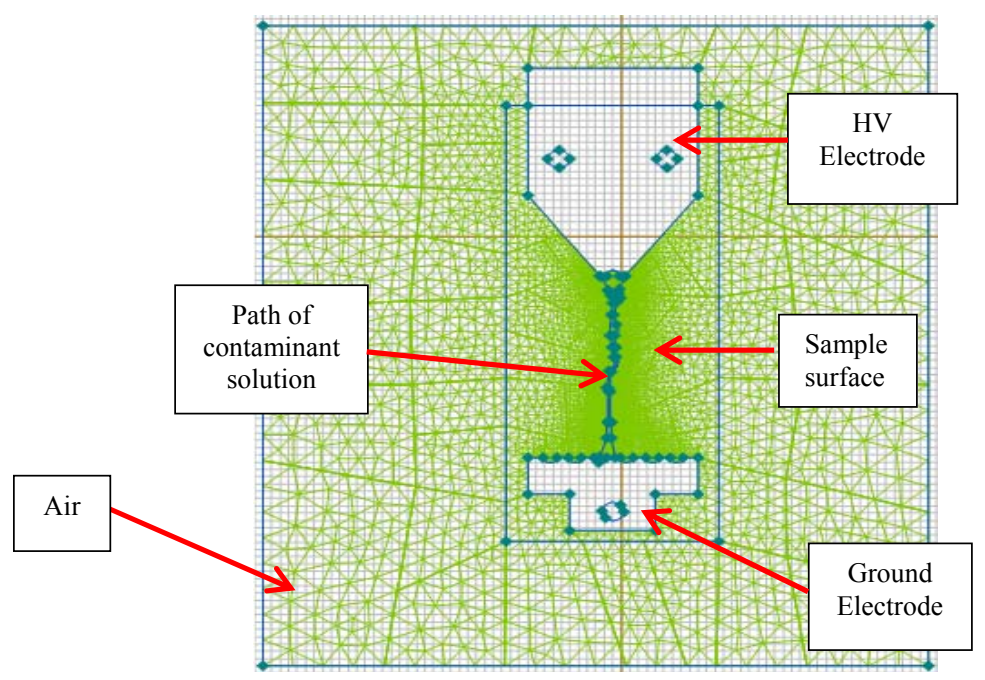

Figure 1. Simulation model of test specimen with the electrodes

The high voltage (HV) terminals were connected to upper electrode and grounded at bottom electrode. The path of contaminant solution was drawn according to the actual pattern captured from the experiment. This simulation was conducted in the AC Conduction analysis. To solve the electric field and current density, the combination of Gauss's Law, Current Continuity Equation and Ohm's Law given in (7), (8) and (9) was applied in this analysis:

$$
\begin{aligned}
& \nabla \cdot \varepsilon E=\rho \\
& \nabla \cdot J=-\frac{\delta \rho}{\delta t} \\
& J=\sigma E
\end{aligned}
$$

where $\rho$ is electric charge density $\left(\mathrm{c} / \mathrm{m}^{3}\right), \varepsilon$ is dielectric constant of dielectric material $\left(\varepsilon=\varepsilon_{r} \varepsilon_{0}\right)$, is the electric conductivity of dielectric material, $J$ is current density $\left(\mathrm{A} / \mathrm{m}^{2}\right)$ and $E$ is electric field strength $(\mathrm{V} / \mathrm{m})$.

\section{RESULTS AND ANALYSIS}

\subsection{Constant Applied Voltage}

In FEM analysis, AC conduction analysis was selected to determine the electric field and current density distribution on the insulator surface caused by alternating currents and voltages in imperfect dielectric media. The solved field simulation profile of the electric field and voltage distribution profile on the insulator surface are shown in Figure 2. The measurement was taken at the red line where contaminant solution was drawn, as in Figure 2. From the distribution of the electric field as shown in Figure 2(a), the electric field distribution was found higher at a center region. The highest electric field distribution appeared at the narrow and edge shape of contaminant water. In this region, ionization occured as the electric field intensity is 
concentrated at the edges. In the IPT test, the contaminant layer was initiated in order to imitate the conditions of hydrophobicity loss in the materials. Hydrophobicity loss of the materials happens when the water droplet has a contact angle less than 90 degrees and has a large surface area with contact of the materials. The contaminant layer was not uniform and evaporation occurred due to leakage of current flow at the thinnest layer of contaminant layer near ground electrode. The thickness of the contaminant layer affects large surface areas differently, causing resistance to reduce; hence theoretically, the leakage current value should be higher at the thinnest contaminant layer. Eventually, dry band arcing will occur when LC reaches the threshold voltage.

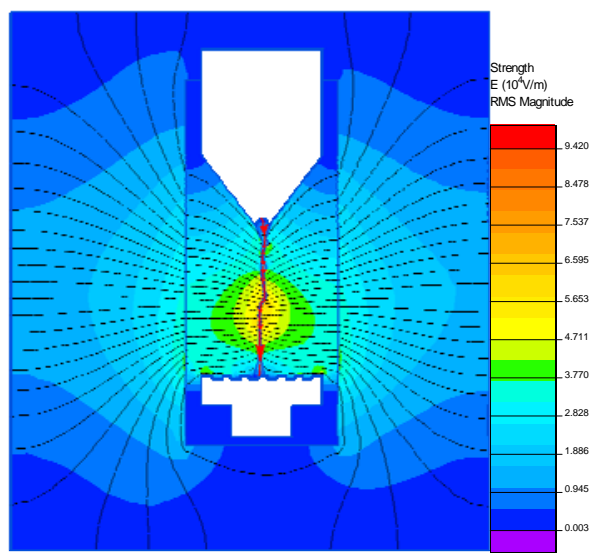

(a)

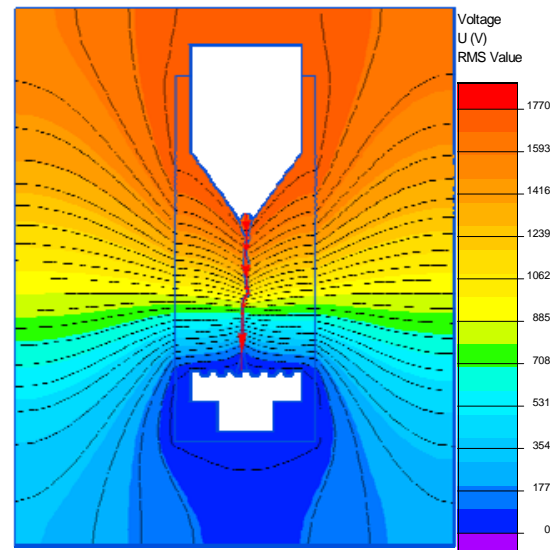

(b)

Figure 2. (a) Electric field distribution, (b) Voltage distribution

A constant voltage was applied at different contaminant flow rate of $0.15 \mathrm{mlmin}^{-1}, 0.30 \mathrm{mlmin}^{-1}$, $0.60 \mathrm{mlmin}^{-1}$, and $0.90 \mathrm{mlmin}^{-1}$. It is worth to mention that the conductivity of the contaminant solution varied with fixed applied voltage. As shown in Table 2, the conductivity of the contaminant solution increased with the increase of the contaminant flow rate. Figure 3 shows the graph of current density and electric field distribution from the $\mathrm{HV}$ electrode to a ground electrode with a constant voltage of $4.5 \mathrm{kV}$. The current density distribution increased with the increase of contaminant water conductivity. The average current density were $0.0673 \mathrm{~A} / \mathrm{m}^{2}, 0.1202 \mathrm{~A} / \mathrm{m}^{2}, 0.1572 \mathrm{~A} / \mathrm{m}^{2}$ and $0.2262 \mathrm{~A} / \mathrm{m}^{2}$ for contaminant flow rate of 0.15 mlmin ${ }^{-1}, 0.30 \mathrm{mlmin}^{-1}, 0.60 \mathrm{mlmin}^{-1}$, and $0.90 \mathrm{mlmin}^{-1}$, respectively. As the contaminant layer became thick, the resistance on the surface reduced and hence added more LC density at that particular location, as shown in Figure 3(a). However, the electric field distribution showed no changes as the voltage was applied. The current density increased near the ground electrode, which wasthe location for the most severe carbon track experimentally $[4,6]$.

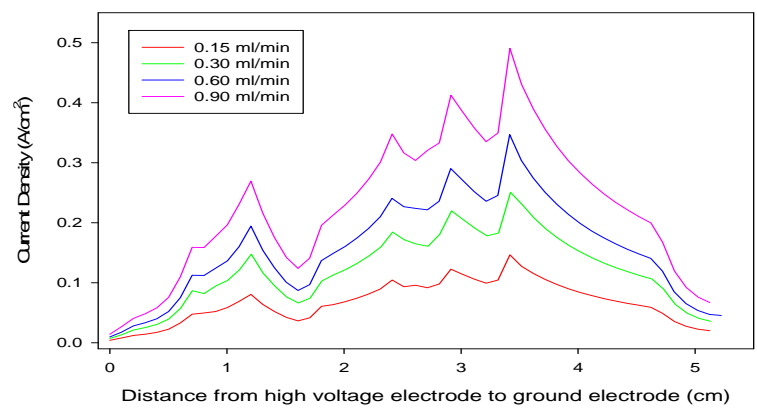

(a) Current density

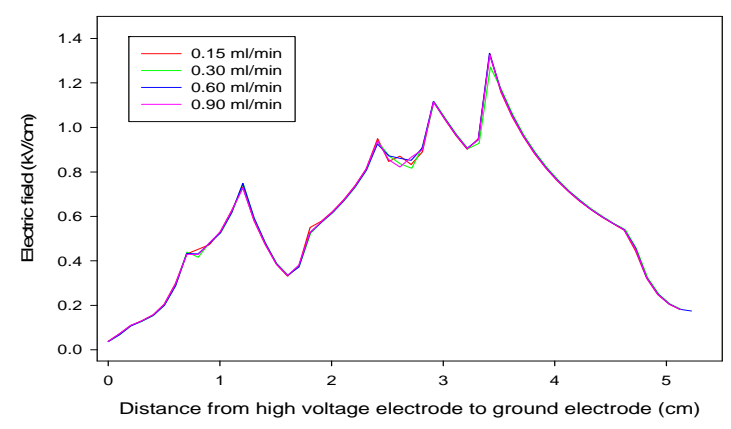

(b) Electric field

Figure 3. Constant voltage of $4.5 \mathrm{kV}$ (a) Current Density (b) Electric Field 


\subsection{Constant Contaminant Flow Rate}

The same method as described in Section 3.1 was then repeated, but the contaminant flow rate was fixed while the applied voltage was varied to $2.5 \mathrm{kV}, 3.5 \mathrm{kV}, 4.5 \mathrm{kV}$ and $6.0 \mathrm{kV}$. Figure 4 shows the graph of current density and electric field for constant flow rate of $0.90 \mathrm{mlmin}^{-1}$ that corresponded to $0.037 \mathrm{Sm}^{-1}$ for electric conductivity. Results in Figure 4 (a) and (b) show that the increase in applied voltage caused the current density and electric field distribution to increase on the insulator surface.

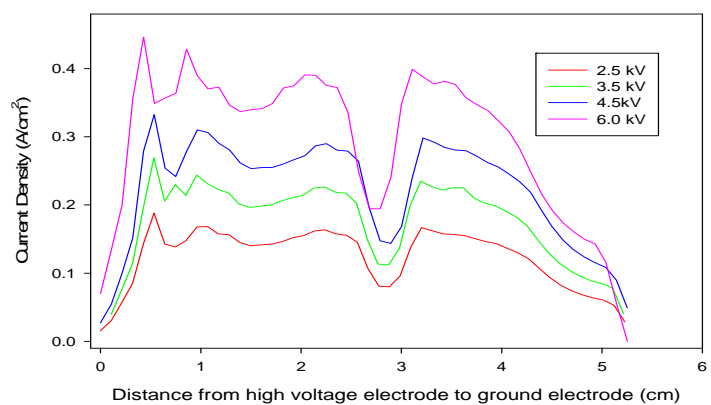

(a) Current Density

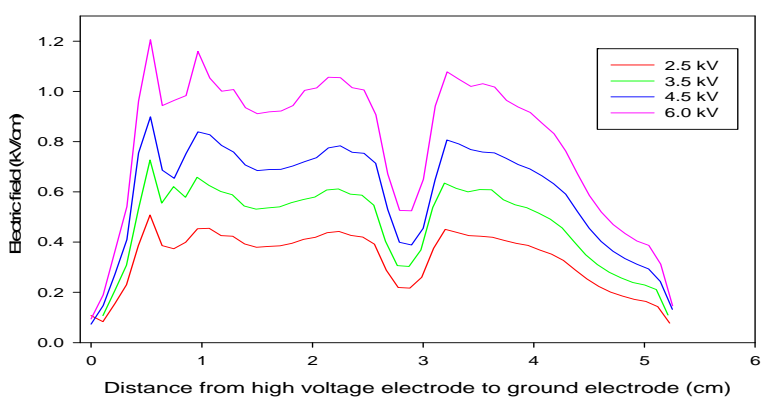

(b) Electric Field

Figure 4. Constant contaminant flow rate of $0.90 \mathrm{ml} / \mathrm{min}$ (a) Current Density (b) Electric Field

Table 3 depicts the maximum current density and electric field value of the constant contaminant flow rate of $0.90 \mathrm{mlmin}^{-1}$, and it was concluded that the increase of applied voltage caused increase in both current density and electric field. The high electric field strength showed increase in current density at certain locations, and hence the electric discharge activity existed on the insulator surface. Higher applied voltage canprovide more energy for electron to be deposited on the solid insulator surface.

The presence of this charge increased the surface conductivity and led to the increase in discharge magnitude. High LC flow will cause non-uniform heating which may lead to dry band arcing, and eventually damage the insulator surface. When heated, it will cause evaporation in the contaminant film. This film will then break up into small portions, and each of them would tend to interrupt a segment of LC and cause a small partial discharge (PD). PD can occur along the surface of the insulator, if the surface tangential of electric field is high enough to cause a breakdown along the insulator surface. The increase of current density and electric field distribution due to the increment of applied voltage could contribute to short tracking of failure time.

Table 3. Current Density and Electric Field for different level of applied voltage in constant contaminant

\begin{tabular}{lcccc}
\multicolumn{1}{c}{ flow rate } & & & \\
\hline Applied voltage $(\mathrm{kV})$ & 2.5 & 3.5 & 4.5 & 6.0 \\
Maximum Current Density (A/cm $\left.{ }^{2}\right)$ & 0.08 & 0.21 & 0.35 & 0.63 \\
Maximum Electric Field $(\mathrm{kV} / \mathrm{cm})$ & 0.70 & 1.06 & 1.33 & 1.70 \\
\hline
\end{tabular}

\section{CONCLUSION}

In investigating electric field and current density distributions on the insulator surface in this study, the geometry plane-parallel is established using Finite Element Analysis. Inclined plane tracking test (IEC 60587) has been used as reference in the simulation. The controlled parameters used to investigate the electric field and current densities have been applied with voltage and contaminant flow rate. The simulation analysis shows that the increase in contaminant flow rate and applied voltage will contribute to the increase in current density and electric field distribution. In addition, the non-uniform electric stress is observed at the centre path of electrode-gap due to the different form of contaminant solution. It is also found that the highest electric stress occurs at the narrow and edge shape of the contaminant solution, along the insulator surface. 


\section{ACKNOWLEDGEMENTS}

The authors gratefully acknowledgement the Malaysia Ministry of Education (MOE) and Universiti Teknologi Malaysia (UTM) for the financial support under the research grants vote number R.J130000.7823.4L133, Q.J130000.2523.03H86 and R.J130000.7823.4F751.

\section{REFERENCES}

[1] Tumiran, T., et al, "Accelerated Aging Effect on Epoxy-polysiloxane-Rice Husk Ash Polymeric Insulator Material", TELKOMNIKA (Telecommunication Computing Electronics and Control), vol 10(4), pp 655-666, 2012.

[2] Syakur A, Berahim H, Tumiran T, Rochmadi R,"Leakage current measurement of epoxy resin compound with silicon rubber", in Electrical Engineering and Informatics (ICEEI), 2011 International Conference Electrical Engineering and Informatics (ICEEI), 2011, pp 1-5, 2011.

[3] Ramirez-Vazquez I, Nava R, "Application of nano particles for the modification of high voltage insulators", IEEE Transactions on Dielectrics and Electrical Insulation, vol 20 (6), pp. 2262-2269, 2013.

[4] Nakamura T, Kozako M, Hikita M, Inoue R, Kondo T, "Experimental investigation on erosion resistance and hydrophobicity of silicone rubber nanocomposite", in 2013 IEEE International Conference on Solid Dielectrics (ICSD), pp 230-233, 2013.

[5] Bian S, Jayaram S, Cherney EA, "Erosion Resistance of Electrospun Silicone Rubber Nanocomposites", IEEE Transactions on Dielectrics and Electrical Insulation, vol 20 (1), pp 185-193, 2013.

[6] Nekeb A, Haddad A, Harid N, Griffiths H, Waters R, "Effects of UV irradiation on textured silicone rubber material", Universities Power Engineering Conference (UPEC), 2012 47th International, pp 1-5, 2012.

[7] Sarkar P, Haddad A, Waters R, Griffiths H, Harid N, Charalampidis P, "Inclined-plane tests of textured silicone rubber Samples", in 2010 International Conference on High Voltage Engineering and Application (ICHVE), pp $532-535,2010$.

[8] Kumagai S, "Leakage current suppression and resistance to tracking and erosion of HTV silicone rubber with added silicone plasticizer", IEEE Transactions on Dielectrics and Electrical Insulation, vol 14(2), pp 384-92, 2007.

[9] Vasudev N, Ganga S, Shivakumara Aradhya R, Pai BL, " Effect of ATH filler content on the performance of silicone rubber by inclined plane tracking and erosion test method", in 2012 IEEE 10th International Conference on the Properties and Applications of Dielectric Materials (ICPADM), pp 1-4, 2012.

[10] Syakur, A., et al., "Electrical Tracking Formation on Silane Epoxy Resin under Various Contaminants", TELKOMNIKA (Telecommunication Computing Electronics and Control), vol 11(1), pp 17-28, 2013.

[11] Jamail NAM, Piah MAM, Muhamedin FL, Kasri NF, Muhamad NA, Kamarudin QE,"Electrical tracking characterization of LLDPE-Natural Rubber blends filled with nanofillers", in 2013 IEEE Conference on Electrical Insulation and Dielectric Phenomena (CEIDP), pp 695-698, 2013.

[12] Padma V, Raghavan VS, "Analysis of Insulation Degradation in Epoxy Insulators Using Finite Element Method", in 2012 Third International Conference on Intelligent Systems, Modelling and Simulation (ISMS), pp 498-503, 2012.

[13] E. Da Silva SMR, "The dependency of water droplet behaviour and LC pattern on electrode configuration", in 2009 Annual Report Conference on Electrical Insulation and Dielectric Phenomena, pp 242-245, 2009.

[14] Andersson J, Guerrero RS, Gubanski SM, Hillborg H, "Tracking behaviour in the presence of conductive interfacial defects", in 2009 CEIDP'09 IEEE Conference on Electrical Insulation and Dielectric Phenomena, pp 230-233, 2009

[15] Sarang B, Basappa P, Lakdawala V,"Effect of water droplets and water films on the electrical performance of practical outdoor insulators", in Conference Record of the 2010 IEEE International Symposium on Electrical Insulation (ISEI), pp 1-6, 2010.

[16] Ilhan S, Ozdemir A, Jayaram SH, Cherney EA, "Simulations of pollution and their effects on the electrical performance of glass suspension insulators", in 2012 Annual Report Conference on Electrical Insulation and Dielectric Phenomena (CEIDP), pp 803-806, 2012.

[17] Illias HA, Chen G, Lewin PL, "Measurement and modelling of partial discharge behaviour in a spherical cavity within a solid dielectric material as a function of cavity diameter", in International Conference on Solid Dielectrics (ICSD), pp 1-4, 2010

[18] Du B, Liu Y, Xia Y, Yang B, Liu B, "Dynamic behavior of water droplet for evaluating outdoor insulator", 2009 ICPADM 2009 IEEE 9th International Conference on the Properties and Applications of Dielectric Materials, pp 272-275, 2009.

[19] Yong Z, Otsubo M, Honda C, Hashimoto Y, Ohno A., "Mechanism for change in leakage current waveform on a wet silicone rubber surface-a study using a dynamic 3-D model", IEEE Transactions on Dielectrics and Electrical Insulation, vol 12 (3), pp 556-565, 2005.

[20] Da Silva E, Rowland SM, "The dependency of water droplet behaviour and leakage current pattern on electrode configuration", in 2009 CEIDP '09 IEEE Conference on Electrical Insulation and Dielectric Phenomena, pp 242245, 2009.

[21] Piah MAM, Darus A, Hassan A., "Electrical tracking performance of LLDPE-natural rubber blends by employing combination of leakage current level and rate of carbon track propagation", IEEE Transactions on Dielectrics and Electrical Insulation, 2005, vol 12 (6), pp 1259-1265.

[22] Standard B. IEC 60587 Electrical insulating materials used under severe ambient conditions-Test methods for evaluating resistance to tracking and erosion. British Standard, pp 1-13, 2007.

Effect of Contaminant Flow-rate and Applied Voltage on the Current Density and ...(F. L. Muhamedin) 


\section{BIOGRAPHIES OF AUTHORS}

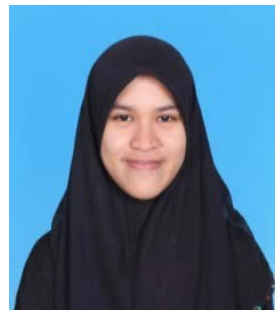

Fatin Liyana Muhamedin (F.L. Muhamedin) was born in Selangor, Malaysia on February 27, 1990. She received the B.E. degree in electrical power engineering from Universiti Technologi Malaysia (UTM) in 2013. Currently, she is pursuing the M.E. degree at Institute of High Voltage and High Current (IVAT) in Faculty of Electrical Engineering, UTM. Her research interests include surface discharge and materials for high voltage insulator.

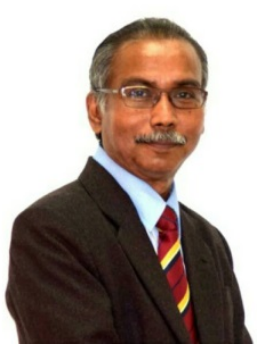

Dr. Mohamed Afendi Mohamed Piah (M.A.M. Piah) is an associate professor at Faculty of Electrical Engineering, Universiti Teknologi Malaysia and a fellow member of the Institute of High Voltage and High Current (IVAT). He is also a Signatory of High Voltage Testing accreditation lab of ISO/IEC 17025. He received the B.Elect. Eng. degree from Universiti Teknologi Malaysia in 1986, M.Sc in Power System from University of Strathclyde, UK in 1990 and $\mathrm{PhD}$ in High Voltage Engineering from Universiti Teknologi Malaysia in 2004. He was appointed as an assistant director (Test and Calibration Division) of IVAT from 1996-2000 and Deputy Director of IVAT from 2007-2009. He has been involved in testing and calibration of high voltage equipments. His research interests include high voltage insulation diagnostic and co-ordination, electrical discharges, polymer nanocomposites insulating materials and insulator condition monitoring.

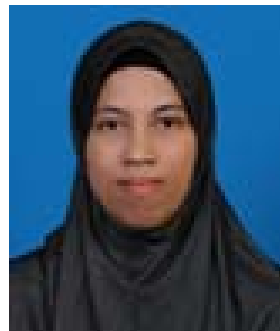

N.A. Othman was born in Johor, Malaysia on January 19, 1986. She received B.Eng in Electrical Engineering from Universiti Teknologi Malaysia (UTM) in 2010. She is currently pursuing Ph.D. degree at Institute of High Voltage and High Current (IVAT) in Faculty of Electrical Engineering, UTM. Her research interest includes the detection and diagnostics of partial discharges and space charge in insulation for condition monitoring.

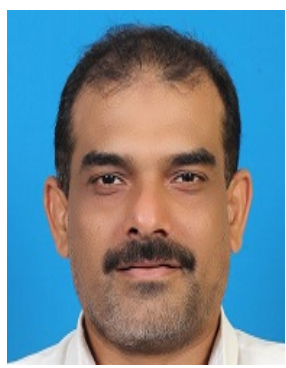

Dr. Nasir Ahmed Algeelani received the B.E. degree in electrical power system from University of Aden, Yemen, Aden, in 1997, the M.E. degree in electrical power system engineering from University Technology Malaysia in 2009 and the Ph.D. degree in high voltage engineering from University Technology Malaysia in 2014. He was a Lecturer with Industrial Technical Institute (ITI) for 25 years, where he is currently a senior lecturer of High Voltage Engineering. At the present he is a postdoctoral candidate at high voltage engineering department at University Technology Malaysia. He has published as authored and co-authored more than 30 papers in various technical journals and conference proceedings. His research interests include highvoltage instrumentation, partial discharge, detection and warning systems and condition monitoring of high power equipment. 